\title{
Endocrine roles of D-aspartic acid in the testis of lizard Podarcis s. sicula
}

\author{
F Raucci, S D'Aniello ${ }^{1}$ and M M Di Fiore \\ Department of Life Sciences, Second University of Naples, Via Vivaldi 43, 81100 Caserta, Italy \\ ${ }^{1}$ Department of Biochemistry and Molecular Biology, Zoological Station of Naples, Villa Comunale, 80121 Napoli, Italy \\ (Requests for offprints should be addressed to M M Di Fiore; Email: MariaM.DiFiore@unina2.it)
}

\begin{abstract}
In the lizard Podarcis s. sicula, a substantial amount of D-aspartate (D-Asp) is endogenous to the testis and shows cyclic changes of activity connected with sex hormone profiles during the annual reproductive phases. Testicular D-Asp content shows a direct correlation with testosterone titres and a reverse correlation with $17 \beta$-estradiol titres. In vivo experiments, consisting of i.p. injections of $2.0 \mu \mathrm{mol} / \mathrm{g}$ body weight of $\mathrm{D}$-Asp or other amino acids, in lizards collected during the three main phases of the reproductive cycle (pre-reproductive, reproductive and post-reproductive period), revealed that the testis can specifically take up and accumulate D-Asp alone. Moreover, this amino acid influences the synthesis of testosterone and $17 \beta$-estradiol in all phases of the cycle. This phenomenon is particularly evident during the pre- and post-reproductive period, when endogenous testosterone levels observed in both testis and plasma were the lowest and $17 \beta$-estradiol concentrations were the highest. D-Asp rapidly induces a fall in $17 \beta$-estradiol and a rise in
\end{abstract}

testosterone at $3 \mathrm{~h}$ post-injection in the testis and at $6 \mathrm{~h}$ post-injection in the blood. In vitro experiments show that testicular tissue converted L-Asp into D-Asp through an aspartate racemase. D-Asp synthesis was measured in all phases of the cycle, but was significantly higher during the reproductive period with a peak at $\mathrm{pH} 6 \cdot 0$. The exogenous D-Asp also induces a significant increase in the mitotic activity of the testis at $3 \mathrm{~h}(P<0 \cdot 05)$ and at $6 \mathrm{~h}(P<0 \cdot 01)$. Induction of spermatogenesis by $\mathrm{D}-\mathrm{Asp}$ is recognized by an intense immunoreactivity of the germinal epithelium (spermatogonia and spermatids) for proliferation cell nuclear antigen (PCNA). The effects of D-Asp on the testis appear to be specific since they were not seen in lizards injected with other D- or L-forms of amino acids with known excitatory effects on neurosecretion. Our results suggest a regulatory role for D-Asp in the steroidogenesis and spermatogenesis of the testis of the lizard Podarcis s. sicula.

Journal of Endocrinology (2005) 187, 347-359

\section{Introduction}

There is a growing body of evidence indicating a role for free endogenous $\mathrm{D}$-aspartic acid (D-Asp) in nervous and endocrine tissue in several animal phyla (D'Aniello et al. 1998a). In the family of neuroexcitatory amino acids, it is now well known that D-Asp has important neurotransmission and neurosecretion roles (Schell et al. 1997, Wolosker et al. 2000). D-Asp is the precursor for the synthesis of $\mathrm{N}$-methyl- D-aspartic acid (NMDA) and the enzyme catalyzing this reaction is the $N$-methyl transferase, as reported in previous work carried out in rats (D'Aniello et al. 2000a,b). D-Asp is localized in various neurons of rat brain, including the hippocampus, and in the hypothalamo-neurohypophyseal system suggesting its involvement in regulating the neurosecretory system (Schell et al. 1997, D'Aniello et al. 2000a, Wang et al. $2000,2002)$. In vertebrates, this amino acid occurs in the nervous tissues of chickens (Neidle \& Dunlop 1990), rats
(Dunlop et al. 1986, D'Aniello et al. 1993, 2000a,b, Hashimoto et al. 1993) and humans (Fisher et al. 1991, 1994). An extremely high content of D-Asp was detected in human brain (Fisher et al. 1991) as well as in the cerebrospinal fluid (Fisher et al. 1994). In addition, D-Asp may participate in brain development, differentiation and functioning (Hashimoto et al. 1993, Hashimoto \& Oka, 1997, Imai et al. 1997, Sakai et al. 1998a) or may be a novel messenger in neuronal and neuroendocrine organs (Schell et al. 1997, Wolosker et al. 2000). Most recent investigations have examined the endocrine system of mammals where D-Asp is well represented in the pineal gland (Imai et al. 1995, Lee et al. 1997, Takigawa et al. 1998), hypothalamus (Fisher et al. 1994, Wang et al. 2002), pituitary (D'Aniello et al. 2000a,b), adrenals (Hamase et al. 1997, Lee et al. 2001) and gonads (D'Aniello et al. 1996, 1998b, Sakai et al. 1998b). Maximal content and transient emergence of D-Asp in these tissues correspond to their morphological and functional maturation (Hashimoto et al. 
1993, Imai et al. 1997). In the adenohypophysis, pineal gland and testis in particular, D-Asp is involved in hormone synthesis and release (Dunlop et al. 1986, Fisher et al. 1991, Hashimoto et al. 1993, Hashimoto \& Oka 1997, D’Aniello et al. 1998b, 2000a,b, Ishio et al. 1998, Takigawa et al. 1998, Wang et al. 2002). The relationship between D-Asp and endocrine activity has been well documented. Developmental changes in levels of D-Asp and testosterone in rat testis parallel each other closely: they increase to maximum levels at sexual maturity. As in testes, D-Asp also increases with age in the pituitary (D'Aniello et al. 1996). Intraperitoneal administration of D-Asp to adult male rats induces D-Asp accumulation in the pituitary gland and testis, followed by a significant increase in luteinizing hormone, testosterone, progesterone (D'Aniello et al. 2000a) and prolactin (D'Aniello et al. $2000 b$ ) in the blood. Moreover, D-Asp is contained in spermatids (Sakai et al. 1998b) and both Leydig (D'Aniello et al. 1998b, Nagata et al. 1999a) and Sertoli cells (D'Aniello et al. 1998b), and in vitro experiments performed on isolated testis demonstrated that this amino acid enhances the production of testosterone (D'Aniello et al. 1996). These data indicate that D-Asp may act as a novel putative regulator of hormonal synthesis. In support of findings in mammals, other studies on lower, seasonal breeding vertebrates have shown the effects of D-Asp on gonads. In the amphibian Rana esculenta, D-Asp occurs in the ovary where it is involved in the control of testosterone release during the sexual cycle (Di Fiore et al. 1998). In the female lizard Podarcis s. sicula, D-Asp enhances follicular production of $17 \beta$-estradiol by up-regulating the local aromatase activity (Assisi et al. 2001). Raucci et al. (2004) demonstrated that D-Asp was rapidly taken up by the testis of injected frogs and its rise was coupled with a significant increase in testosterone levels and a consequent increase in mitotic activity in the testis. On the other hand, D-Aspartate may play a role in hormonal regulation, as it stimulates testosterone synthesis in the testis, increasing the mRNA level of a steroidogenic acute regulatory protein (StAR) (Nagata et al. 1999b). These findings for D-Asp suggest it has different targets in the sex steroid production machinery depending on the species and/or the sex, i.e. the amino acid operates differently, favoring androgen production in males and estrogen production in females. Testosterone is a well-known prerequisite for normal spermatogenesis (see for reviews, Zirkin (1993) and Sharpe (1994)). In the roe deer (Capreolus capreolus), a typical seasonal breeder, the peak in testosterone coincides with maximal meiotic activity of the testis and with spermatogonial proliferation. This evidence, already known in most vertebrates, strongly suggests the importance of testosterone for sperm production (Roelants et al. 2002). Furthermore, the protein proliferating cell nuclear antigen (PCNA) is essential for the proliferation of the spermatogonia. It is also utilized in cell cycle control through direct interaction with cyclin and cyclin-dependent kinase (cdk) complex, where it allows progression through the G1/S boundary (Zhang et al. 1993). For these reasons, PCNA is utilized as an endogenous and molecular marker of mitotic and testicular epithelial proliferation (Chieffi et al. 2000, 2001).

Except for the data reported on male frogs, there are no studies yet available on D-Asp presence and its effect on the testis of lower vertebrates. Seasonal breeders are good models for studying the involvement of D-Asp on the testis because the effects of this molecule can be compared in response to the different phases of spermatogenesis. Therefore, to gather information on this aspect of $\mathrm{D}-\mathrm{Asp}$ function, we investigated the occurrence of endogenous D-Asp in the testis of lizard, Podarcis s. sicula. To gain insight into the functional significance of $\mathrm{D}$-Asp in this organ, we studied the role of this amino acid in lizards collected during the main phases of their reproductive cycle. We studied the uptake of D-Asp in the testis and its putative role in both steroidogenesis (sex hormones in the testis and plasma evaluated during the cycle and from in vivo experiments) and spermatogenesis (immunohistochemistry technique using PCNA antibody). Finally, we attempted to determine whether the D-Asp present in the gonad could come from a local conversion of L-Asp by a specific racemase.

\section{Materials and Methods}

\section{Reproductive aspects of the sexual cycle in male Podarcis s. sicula}

The reproductive cycle of this lizard has been widely studied using both morphologic (Botte \& Angelini 1980, Angelini \& Botte 1992) and endocrine (Botte \& Angelini 1980, Andò et al. 1990, 1992, Paolucci et al. 1992) parameters. Generally, at the beginning of March the lizards emerge from winter shelter; gonads and secondary sexual characters (SSCs) begin to develop and are functional until the end of June-beginning of July. From March to April, male lizards are engaged in fights (aggressive phase) that are linked to reproductive territory assessment (reproductive period). At the end of Aprilbeginning of May, courtship and mating begin and last for several weeks (mating phase). In July, when the temperature is still favorable for reproduction, a refractory period induces a block of spermatogenesis and the regression of SSCs (refractory phase): this phase is considered the post-reproductive period. In October, spermatogenesis resumes and some sperms are produced, but there is no spermiation or SSCs. From November to March, external temperatures decline and the lizards undergo semihibernation (pre-reproductive period).

\section{Animals}

Taking into account the reproductive characteristics, adult Podarcis s. sicula males were captured in the countryside 
(Caserta, Italy) during the pre-reproductive (NovemberFebruary), reproductive (March-May) and postreproductive (July) phases. The animals used were 2-3 years old and had a body weight of about $8-9 \mathrm{~g}$. Five animals were killed in the field, others were transferred to a laboratory terrarium with a photothermal regimen consistent with the period of the year: in the prereproductive period, $8 \mathrm{~h}$ light: $16 \mathrm{~h}$ darkness at $10-12{ }^{\circ} \mathrm{C}$; in the reproductive period, $12 \mathrm{~h}$ light: $12 \mathrm{~h}$ darkness at $22-24{ }^{\circ} \mathrm{C}$; in the post-reproductive period, $16 \mathrm{~h}$ light: $8 \mathrm{~h}$ darkness at $32-34^{\circ} \mathrm{C}$. The humidity was maintained at about $50-60 \%$. The animals were given a regular supply of mealworms and fresh vegetables and were allowed to feed ad libitum. Mortality rates were low $(<10 \%)$. The experiments were carried out on lizards caught in the three main phases of their reproductive cycle. Lizards were assigned to different groups according to treatments (see below). Each group was composed of five animals.

\section{Samples}

Soon after capture, several animals were anesthetized by short cold exposure; blood was collected through a heparinized glass capillary inserted into the heart. Blood samples were centrifuged at $800 \mathrm{~g}$ for $15 \mathrm{~min}$ and the resulting plasma was stored at $-20{ }^{\circ} \mathrm{C}$ for sex steroid analyses. From each animal, liver and testes were rapidly dissected out. One testis and liver sample were frozen in liquid nitrogen, while the other testis was fixed by immersion in Bouin's fluid and processed for histology and immunohistochemistry.

The methods of capture and dissection and the captive rearing conditions were in accordance with Italian law (D. L.vo 116/92) and were authorized by the appropriate Italian government administrative office (Servizio Veterinario della A.S.L. 44, Prot. Vet. 22/95).

In vivo experiments: short-term treatment with $D$-Asp and other D-/L-amino acids

Short-term experiments were carried out by injecting D- and L-forms of amino acids into lizards caught in three main phases of their reproductive cycle. Lizards, sorted into 5 groups, 25 animals in each, were treated as follows: lizards from groups 1, 2, 3 and 4 received i.p. $2 \cdot 0 \mu \mathrm{mol} / \mathrm{g}$ body weight of different amino acids dissolved in $100 \mu \mathrm{l}$ reptilian physiological saline $(0 \cdot 7 \% \mathrm{NaCl})$. This dose was chosen on the basis of preliminary experimental tests. Namely, group 1 was injected with L-Asp, group 2 with D-glutamate (D-Glu), group 3 with L-glutamate (L-Glu), group 4 with D-alanine (D-Ala). The lizards from group 5 were injected with vehicle alone (saline solution) and used as controls. Plasma, liver and testes were collected at different times after the last injection $(0,3,6,15$ and $24 \mathrm{~h})$ and utilized as described above. The amino acids were purchased from Sigma.
In other experiments, the D-Asp uptake by testis and the concomitant levels of testicular and plasma steroid hormones were studied. Lizards, belonging to main phases of their reproductive cycle, were distributed in two groups (25 animals each). Animals from the first group were injected i.p. with $2.0 \mu \mathrm{mol} \mathrm{D}-\mathrm{Asp} / \mathrm{g}$ body weight dissolved in $100 \mu \mathrm{l}$ of reptilian saline. The lizards from the second group received $100 \mu \mathrm{l}$ saline solution and, therefore, were used as controls. Five injected lizards from each group were killed at set times within a period of $24 \mathrm{~h}(0$, $3,6,15$ and $24 \mathrm{~h}$ after the injection respectively). The lizards were utilized as previously reported for experiments on D-Asp uptake, sex steroid concentrations and immunoreaction assay (see below).

\section{Sex steroid assays in plasma and testis}

Sex steroid determinations in the plasma were conducted utilizing enzyme immunoassay (EIA) kits (Adaltis Italia, spa, Italy). The following limits of detection were observed: for testosterone, sensitivity was $50 \mathrm{pg} / \mathrm{ml}$ (intraassay variability $4 \cdot 0 \%$, inter-assay variability $9 \cdot 0 \%$ ); for $17 \beta$-estradiol, sensitivity was $6 \mathrm{pg} / \mathrm{ml}$ (intra-assay variability $6 \cdot 0 \%$, inter-assay variability $7 \cdot 5 \%$ ). The addition of D-Asp to the standard curve did not modify the assay sensitivity. Plasma samples $(100 \mu \mathrm{l})$ were vortexed with ethyl ether $(1: 10, \mathrm{v} / \mathrm{v})$ for $5 \mathrm{~min}$ and centrifuged at $3000 \boldsymbol{g}$ for $10 \mathrm{~min}$. The upper phase (ethyl ether) was transferred to a glass tube. Two extractions were performed. The pooled ether phases were left to evaporate on a hot plate at $40-50{ }^{\circ} \mathrm{C}$ under a hood. The residue was dissolved in a $0.5 \mathrm{ml}$ sodium phosphate buffer $0.05 \mathrm{M}, \mathrm{pH} 7 \cdot 5$, containing BSA at a concentration of $10 \mathrm{mg} / \mathrm{ml}$, and then utilized for the assay. Tissue samples (testis) were homogenized 1:10 (w/v) with distilled water. The homogenate was then mixed vigorously with ethyl ether $(1: 10 \mathrm{v} / \mathrm{v})$ and the ether phase was withdrawn after centrifugation at $3000 \mathrm{~g}$ for $10 \mathrm{~min}$. Three extractions were performed. Pooled ether extracts were dried and then utilized for the enzyme immunoassays as previously reported (Di Fiore et al. 1998). Sex steroid recovery was $85 \%$ from plasma and $80 \%$ from tissues. Steroid recovery was assessed by parallel processing of tissue or plasma samples to which known amounts of steroids had been added prior to extraction and assay.

\section{Preparation of samples for amino acid determination}

Testis and liver samples were homogenized with $0.5 \mathrm{M}$ perchloric acid (PCA) in a 1:10 ratio and centrifuged at $30000 \boldsymbol{g}$ for $20 \mathrm{~min}$. The supernatant was brought to $\mathrm{pH}$ $7 \cdot 5-8.5$ by the addition of $5 \mathrm{M} \mathrm{KOH}$, cooled for $30 \mathrm{~min}$ at $0{ }^{\circ} \mathrm{C}$, and the potassium perchlorate precipitate was removed by centrifugation as described above. The supernatant was adjusted to a $\mathrm{pH}$ of about 2.5 with $1 \mathrm{M}$ $\mathrm{HCl}$, and the amino acids were purified on a cation exchange column (AG 50W-X8 resin, hydrogen ionic 
form, 200-400 mesh, BioRad). The sample was loaded on a column $(1 \times 3 \mathrm{~cm})$ equilibrated with $0.01 \mathrm{M} \mathrm{HCl}$, and, after washing with $10 \mathrm{ml}$ of $0.01 \mathrm{M} \mathrm{HCl}$, it was eluted with $8 \mathrm{ml}$ of $4 \mathrm{M} \mathrm{NH}_{4} \mathrm{OH}$. The eluates were dried by evaporation in small Petri dishes on a hot plate at 40-60 ${ }^{\circ} \mathrm{C}$ under a hood. The dry eluates were dissolved in $1 \mathrm{ml}$ of $0.01 \mathrm{M} \mathrm{HCl}$. They were then purified by slowly passing through a Sep-pak C-18 cartridge (300 mg; Waters, Milan, Italy) which had been previously activated with methanol or acetonitrile and washed with distilled water. To recover the amino acids from these eluates, the cartridge was eluted twice with $2 \mathrm{ml}$ of $0.01 \mathrm{M} \mathrm{HCl}$. The resulting eluates were combined, and dried using a Savant centrifuge or left to evaporate in small Petri dishes at $40-50{ }^{\circ} \mathrm{C}$ under the hood. The dry residues were then dissolved in $200 \mu \mathrm{l}$ of $0 \cdot 01 \mathrm{M} \mathrm{HCl}$ and analyzed for D-Asp content.

\section{$D-A s p$ assay}

The D-Asp was determined with an HPLC assay using the o-phthaldialdehyde/ $N$-acetyl-L-cysteine (OPA-NAC) method and using the D-aspartate oxidase (D-AspO) (EC $1 \cdot 4 \cdot 3 \cdot 1)$ an oxidative enzyme that oxidizes D-Asp. This method has been fully described in a previous paper (Di Fiore et al. 1998). In this study the D-AspO enzyme was obtained by overexpression and purified according to the procedure described previously (Negri et al. 1999). A standard curve was obtained using a mixture containing 17 different L-amino acids plus D-Asp, each at concentrations between 10 and 100 pmol (D'Aniello et al. 2000a).

In vitro experiment: biosynthesis of $D-A s p$ by racemase activity

To verify whether D-Asp is biosynthesized from $\mathrm{L}-\mathrm{Asp}$, via an aspartate racemase, we measured the racemase activity by evaluating the in vitro conversion rate of L-Asp into D-Asp. Testis and liver samples (five for each period) were homogenized $(1: 10 \mathrm{w} / \mathrm{v})$ in $0.05 \mathrm{M}$ sodium phosphate buffer, $\mathrm{pH} 7 \cdot 4$, and centrifuged at $30000 \boldsymbol{g}$ for $30 \mathrm{~min}$. Then $50 \mu \mathrm{l}$ of the homogenate were mixed with $50 \mu \mathrm{l}$ of $0.5 \mathrm{M} \mathrm{L}$-Asp (or with other L-amino acids) in citrate buffer at different values of $\mathrm{pH}$ in the range $4 \cdot 0-8 \cdot 0$ and incubated at $37^{\circ} \mathrm{C}$ for $120 \mathrm{~min}$. Control samples contained all components except L-amino acids. Incubations were stopped by rapid freezing in an ice-bath. The amino acids present in the samples were extracted with $1.0 \mathrm{M}$ PCA. Preformed D-Asp was determined using HPLC as described above.

\section{Histology}

After dissection, lizard testes were rapidly removed and fixed in Bouin's fluid. The histological morphology of testes were studied in paraffin sections $(5 \mu \mathrm{m})$ stained with hematoxylin and eosin (HE), as described in Mazzi (1977).

\section{PCNA immunohistochemistry}

To assess cell proliferation, PCNA immunohistochemistry was performed according to the procedure reported in Chieffi et al. (2000). Fixed lizard testes were serially dehydrated in ethanol and cleared in xylene. Paraffin sections $(5 \mu \mathrm{m})$ were incubated with mouse monoclonal antibody against recombinant PCNA (Dako, Milan, Italy) at a dilution of 1:300 with 10\% BSA, followed by incubation with goat anti-mouse IgG (1:500). The conventional avidin-biotin complex (ABC) procedure was used (Hsu et al. 1981). The peroxidase activity was developed with the use of a filtered solution of $5 \mathrm{mg}$ of 3-3'-diaminobenzidine tetrahydrochloride (DAB; Sigma) dissolved in $15 \mathrm{ml}$ of Tris buffer $0.05 \mathrm{M}, \mathrm{pH} \mathrm{7.6}$, and $0.03 \% \mathrm{H}_{2} \mathrm{O}_{2}$. Sections were mounted with a synthetic medium. The following controls were performed: (1) omission of the primary antibody; (2) substitution of the primary antiserum with pre-immune serum (Dako) diluted 1:500 in blocking buffer; no immuno-staining was observed after any of the control procedures. A section of testis from Rana esculenta was used as the positive control, as described in Raucci et al. (2004).

\section{Morphometry}

Five randomly chosen sections of testis (PCNA immunostained) for each animal of each experimental group were viewed at a magnification of $\times 1000$ using an image analyzer system. The morphological parameter measured was the number of immunoreactive elements for PCNA in $1 \mathrm{~mm}^{2}$ of the testis germinal epithelium. Morphometric analysis consisted of digitization of transverse sections viewed under a Nikon Eclipse E600 light microscope with an attached JVCTK-C1381 photocamera connected to a Pentium II computer running Lucia ScMeas on Mutech software.

\section{Statistical analysis}

Data were compared by ANOVA followed by Duncan's test for multi-group comparison and Student's $t$-test for betweengroup comparison. All data were expressed as means \pm S.D The level of significance was taken at $P<0 \cdot 01$ and $P<0 \cdot 05$. In addition, the correlation coefficients $(r)$ between D-Asp content in the testis and both plasma and testicular concentrations of steroid hormones were calculated.

\section{Results}

Endogenous D-Asp content in the testis and sex hormone concentrations in the testis and plasma during the annual reproductive cycle

Table 1 reports the profiles of endogenous levels of $\mathrm{D}$-Asp and sex hormones (testosterone and $17 \beta$-estradiol) in the 
Table 1 Endogenous D-Asp content in the testis and testosterone and $17 \beta$-estradiol levels in the testis and plasma of the lizard Podarcis $S$. sicula, during the main phases of the reproductive cycle

\begin{tabular}{|c|c|c|c|c|c|}
\hline & \multirow[b]{2}{*}{$\begin{array}{l}\text { D-Asp } \\
(\mathrm{nmol} / \mathrm{g})\end{array}$} & \multicolumn{2}{|l|}{ Testis } & \multicolumn{2}{|l|}{ Plasma } \\
\hline & & $\begin{array}{l}\text { Testosterone } \\
(\mathrm{ng} / \mathrm{g})\end{array}$ & $\begin{array}{l}\text { 17ß-estradiol } \\
(\mathrm{pg} / \mathrm{g})\end{array}$ & $\begin{array}{l}\text { Testosterone } \\
(\mathrm{ng} / \mathrm{ml})\end{array}$ & $\begin{array}{l}\text { 17 } \beta \text {-estradiol } \\
(\mathrm{pg} / \mathrm{ml})\end{array}$ \\
\hline \multicolumn{6}{|l|}{$\begin{array}{l}\text { Phase of the } \\
\text { reproductive cycle }\end{array}$} \\
\hline Pre-reproductive & $17 \cdot 0 \pm 1 \cdot 2$ & $35 \cdot 0 \pm 4 \cdot 0$ & $11 \cdot 5 \pm 0 \cdot 9$ & $8 \cdot 0 \pm 0 \cdot 9$ & $726 \pm 212$ \\
\hline Reproductive & $30 \cdot 0 \pm 2 \cdot 3$ & $50 \cdot 0 \pm 4 \cdot 9$ & $7 \cdot 5 \pm 0 \cdot 6$ & $160 \cdot 0 \pm 9 \cdot 7$ & $217 \pm 108$ \\
\hline Post-reproductive & $3 \cdot 5 \pm 0 \cdot 6$ & $25 \cdot 0 \pm 1 \cdot 4$ & $33 \cdot 5 \pm 3 \cdot 4$ & $30 \cdot 0 \pm 3 \cdot 1$ & $1251 \pm 324$ \\
\hline
\end{tabular}

Each value represents the mean \pm S.D. of five determinations.

D-Asp: pre-reproductive versus reproductive, $P<0 \cdot 01$; reproductive versus post-reproductive, $P<0 \cdot 01$.

Testosterone in testis and plasma: pre-reproductive versus reproductive, $P<0 \cdot 01$; reproductive versus post-reproductive, $P<0 \cdot 01$.

$17 ß$-estradiol in testis: pre-reproductive versus post-reproductive, $P<0 \cdot 05$; reproductive versus post-reproductive, $P<0 \cdot 01$.

$17 ß$-estradiol in plasma: pre-reproductive versus reproductive, $P<0 \cdot 01$; reproductive versus post-reproductive, $P<0 \cdot 01$.

testis of adult male lizards, Podarcis s. sicula, collected during the major phases of the sexual cycle. The plasma levels of sex hormones are also reported. It should be noted that steroid hormones are synthesised by the gonads, rapidly released into the plasma, and do not accumulate in the testis. Endogenous D-Asp occurred in the testis during all periods of the cycle and its level underwent significant variations depending on the reproductive phase. The D-Asp level was significantly higher during the reproductive period than in pre- and post-reproductive periods (1.76- and 8.57-fold respectively). Likewise, testosterone concentration in the testis was higher in the reproductive phases and low in pre- and post-reproductive phases (1.43- and $2 \cdot 0$-fold respectively). In contrast, the $17 \beta$-estradiol level was low in pre-reproductive and reproductive phases but significantly higher during the post-reproductive phase (2.9- and 4.5-fold respectively). The sex hormone levels in the plasma reflected those in the gonads, although in the plasma testosterone level was much higher in the reproductive phase. Comparison of free D-Asp content present in the testis with sexual steroid levels revealed a positive correlation between D-Asp and testosterone throughout the annual cycle $(r=0.992$, $P<0 \cdot 01, n=5$ in the testis and $r=0 \cdot 784, P<0 \cdot 01, n=5$ in the plasma) and a negative correlation between $D-A s p$ and $17 \beta$-estradiol $(r=-0.932, P<0 \cdot 01, n=5$ in the testis and $r=-0.999, P<0 \cdot 01, n=5$ in the plasma).

$D$-Asp uptake in the testis and in vivo effects of $D$-Asp on sex hormone levels in response to $D$-Asp treatment

In adult male Podarcis s. sicula, the i.p. injection of D-Asp $(2 \cdot 0 \mu \mathrm{mol} / \mathrm{g}$ body weight $)$ was followed by its significant, although temporary, uptake by the testis in all sexual cycle stages. In the pre-reproductive phase (Fig. 1A) D-Asp was rapidly taken up by the testis so that $3 \mathrm{~h}$ after injection its concentration in the tissue was about seven times greater than the value observed in animals injected with the saline alone (from $17 \cdot 0 \pm 1 \cdot 2$ to $120 \cdot 1 \pm 9.9 \mathrm{nmol} / \mathrm{g}$ tissue; about 7-fold). D-Asp levels were still high at 6 and $15 \mathrm{~h}$ after injection and then reached a near-baseline value within $24 \mathrm{~h}(23.0 \pm 1.7 \mathrm{nmol} / \mathrm{g}$ tissue $)$. In the reproductive period (Fig. 1B) D-Asp accumulated in the testis, peaking at the same set time observed in the prereproductive period $(3 \mathrm{~h})$, although its uptake was only twice as much. Furthermore, basal values were rapidly reached within 15-24 h. D-Asp was also rapidly taken up by the testis in the post-reproductive period (Fig. 1C) and $3 \mathrm{~h}$ after injection its levels were about 30 times greater than the endogenous content. At $6 \mathrm{~h}$ after injection its levels were still high, but were successively decreasing at 15 and $24 \mathrm{~h}$. In the liver (used as control tissue) the concentration of $\mathrm{D}$-Asp in each period of the cycle was significantly higher than in the testis. Following injection of $2.0 \mu \mathrm{mol} / \mathrm{g}$ body weight of $\mathrm{D}$-Asp the amino acid accumulated 2-3 times more but remained unchanged during the cycle (data not shown). The uptake of other D-/ L-amino acids by the testis was evaluated, but was much lower than for D-Asp (data not shown).

The D-Asp administration affected the levels of sex hormones. In the pre-reproductive period (Fig. 1Ai), $3 \mathrm{~h}$ after D-Asp injection, a significant increase of testicular testosterone was observed (from $35 \cdot 0 \pm 4 \cdot 0$ to $112 \cdot 7$ $\pm 10.9 \mathrm{ng} / \mathrm{g}$ tissue). This effect also appeared in circulation (plasma, Fig. 1 Aii) when the testosterone peaked at $6 \mathrm{~h}$ after injection (from $8 \cdot 0 \pm 0 \cdot 9$ to $45 \cdot 3 \pm 4 \cdot 7 \mathrm{ng} / \mathrm{ml}$ plasma). Successively, in both testis and plasma, the testosterone concentration reached baseline within $24 \mathrm{~h}$. The changes in 17 $\beta$-estradiol after injection of $\mathrm{D}$-Asp were different. Estradiol concentrations in testes decreased at $3 \mathrm{~h}$ (from $11.5 \pm 0.9 \mathrm{pg} / \mathrm{g}$ to $3 \cdot 0 \pm 0.7 \mathrm{pg} / \mathrm{g}$ tissue; Fig. 1Ai) and in the plasma at $6 \mathrm{~h}$ (from $0 \cdot 70 \pm 0 \cdot 2$ to $0 \cdot 2$ $\pm 0 \cdot 1 \mathrm{ng} / \mathrm{ml}$ plasma; Fig. 1 Aii). However, this effect appeared to be reversible because plasma and testicular levels of $17 \beta$-estradiol returned to baseline values within $24 \mathrm{~h}$ of treatment. In the reproductive and postreproductive period, similar sex hormone profiles were observed. Both testosterone increase and $17 \beta$-estradiol 


\section{Pre-Reproductive}

A

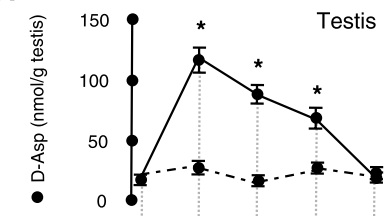

Ai

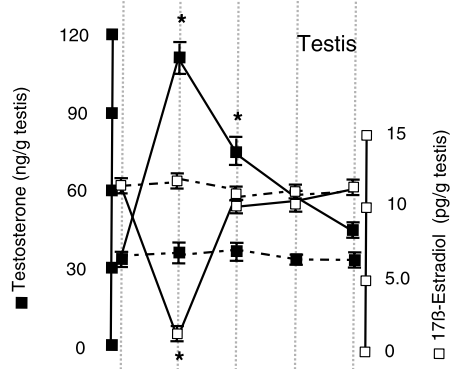

Aii

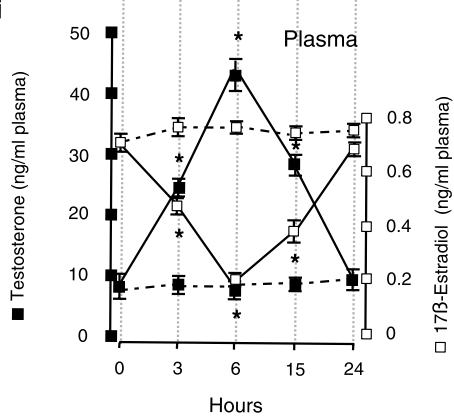

Reproductive

B

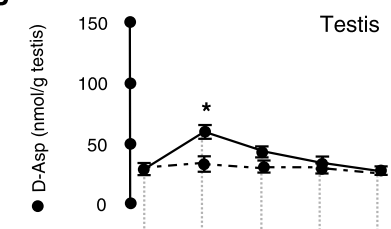

Bi

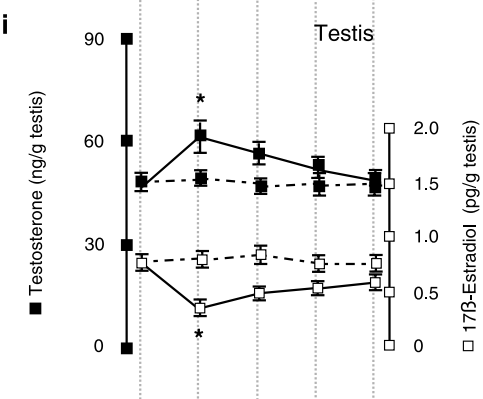

Bii

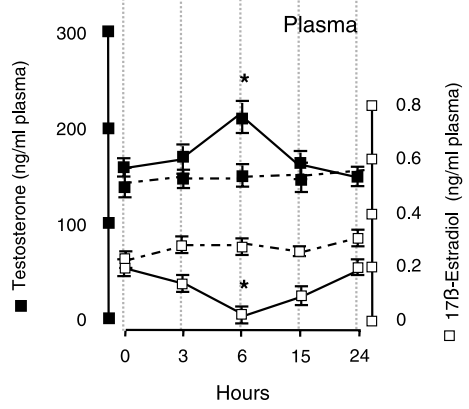

C

Post-Reproductive

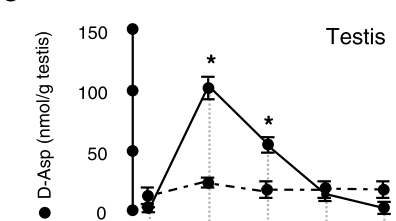

Ci

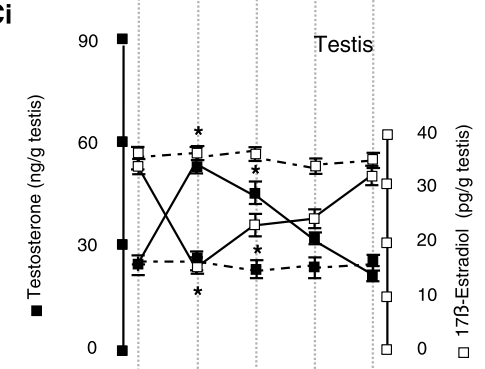

Cii

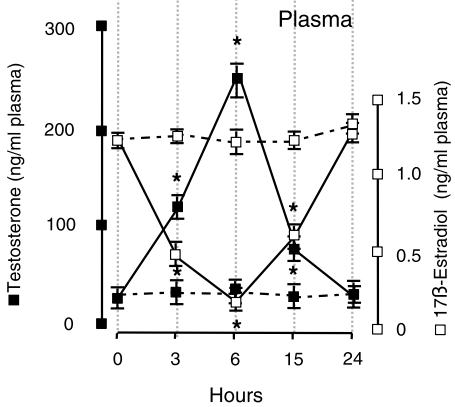

Figure 1 Uptake of D-Asp (A, B, C - - and - -

- -) and concentrations of steroid hormones (testosterone, - $\square$ - and - - - $\mathbf{-}-$ - -; $17 \beta$-estradiol, $-\square-$ and - - - $\square$ - - ) in both testis ( $\mathrm{Ai}, \mathrm{Bi}$ and $\mathrm{Ci}$ ) and plasma (Aii, Bii and Cii) during the reproductive cycle. Animals were injected at time 0 either with D-Asp or with saline solution. Continuous lines represent D-Asp-treated animals, dashed lines represent control animals. Each value represents the mean \pm S.D. of five determinations. ${ }^{*} P<0 \cdot 01$ versus time 0 .

decrease were registered at $3 \mathrm{~h}$ in the testis and at $6 \mathrm{~h}$ in the plasma. Moreover, it is interesting to note that during the reproductive period the variation of hormone concentrations was less than in the other phases of the cycle. This phenomenon could be due to the highest endogenous (physiological) concentration of D-Asp in testis during the reproductive period. In fact, D-Asp was at the highest level in the cycle and therefore further stimulation with exogenous D-Asp had no effect on steroid response. D-Asp uptake and its effect on the steroid levels were correlated to the physiological period's concentration of this D-enantiomer and the steroid hormones (Fig. 1).

In vitro experiment: biosynthesis of $D$-Asp by racemase activity

In order to verify whether D-Asp is locally synthesized by L-Asp through an aspartate racemase we measured the racemase activity by evaluating the in vitro rate conversion of L-Asp into D-Asp during the reproductive cycle (Fig. 2).
Testis and liver tissue homogenates were incubated with L-Asp or other amino acids under different $\mathrm{pH}$ values. In both tissues the conversion rate (L-Asp/D-Asp) was the highest when the in vitro incubation was carried out at pH 6.0. Testicular tissue converted L-Asp into D-Asp in all phases of the cycle and D-Asp biosynthesis only significantly varied during the reproductive period, reaching its maximal level $(239 \cdot 0 \pm 21 \cdot 4 \mathrm{nmol} / \mathrm{g}$ tissue, $P<0 \cdot 01)$ when the endogenous content of free $\mathrm{D}$-Asp and testosterone, measured in the testis, was maximum. In the liver (control tissue) racemase activity was observed but remained unchanged through the cycle (data not shown).

\section{Histology}

The histological morphology of the testis shows that in the seminiferous tubules of treated animals (Fig. 3B, C and D) the germinal epithelium was richer in cellular differentiating elements than in the animals injected with saline alone (Fig. 3A). Spermatogonia (SPG) are observed near 


\section{$\multimap$ Reproductive period}

$\rightarrow-$ Pre-reproductive period

$\rightarrow$ Post-reproductive period

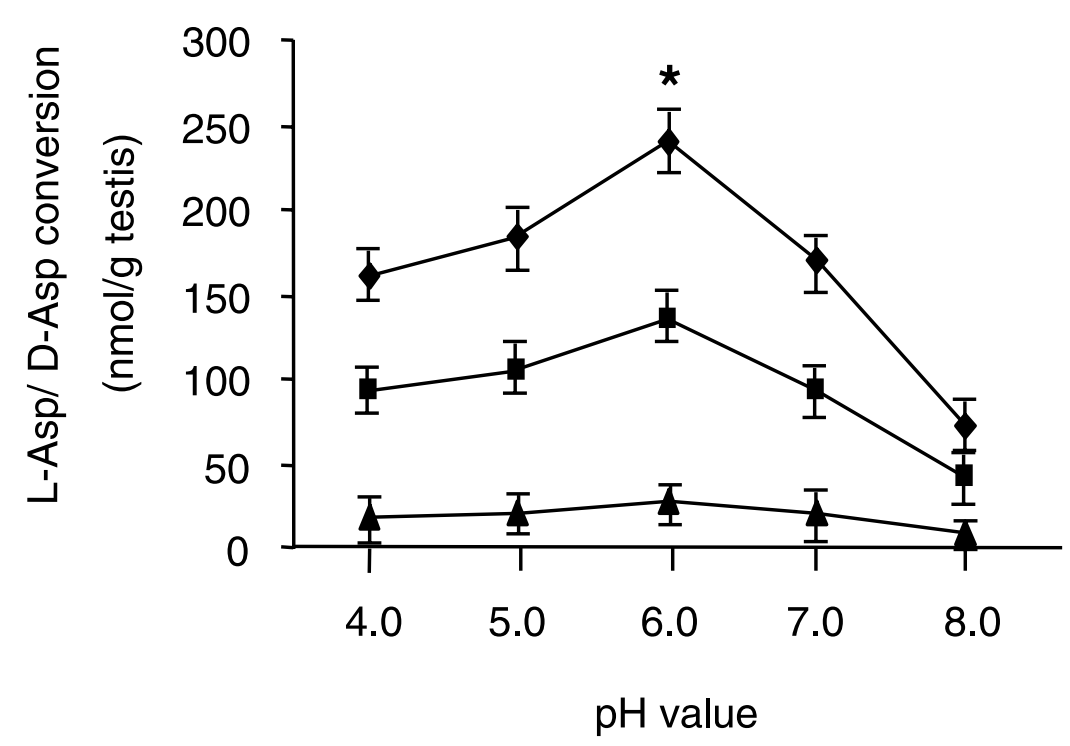

Figure 2 Aspartate racemase activity during the reproductive cycle. Each value represents the mean \pm S.D. of five determinations. $\bullet$, reproductive period; pre-reproductive period; $\boldsymbol{\Lambda}$, post-reproductive period. ${ }^{*} P<0.01$ versus pre- and post-reproductive periods.

the basement membrane of the seminiferous ephitelium in all experimental groups (Fig. 3). Two morphologies of SPG can be distinguished: type I and type II SPG. Type I SPG (Fig. 3A-D, white arrows) are ovoid and have one flattened cellular surface resting directly on the basement membrane. Their nuclei contain prominent nucleoli and heterochromatin concentrated close to the nuclear membrane. Type II SPG (Fig. 3A-D, black arrows) nuclei are round and contain large globules of heterochromatin dispersed throughout the nucleoplasm. Type II SPG undergo meiotic division to produce spermatids (SPDs). SPDs are of a smaller size and so are easily distinguished from the larger type I and II SPG (Fig. 3-D, white arrowheads). The nuclei are spherical, centrally localized and have a distinct acrosome vesicle in direct contact with the nuclear envelop. Elongation of the apical region of the nucleus, nuclear condensation and cytoplasmic elimination produce elongated spermatids with short flagella. At 3 and $6 \mathrm{~h}$ after $\mathrm{D}-\mathrm{Asp}$ injection the elongated spermatids can be seen at the lumen proximity (Fig. 3B and C, black arrowheads). No mature spermatozoa are observed in the lumen of seminiferous tubules either in controls or treated animals.

\section{PCNA immunohistochemistry and morphometry}

Immunohistochemistry reactions, carried out on serial sections of testis, revealed the presence of PCNA protein in the gonad in each period of the reproductive cycle. We found that immunoreactivity for PCNA was abundant in the cytoplasm and nucleus of SPG and in the nucleus of early stage I SPG during spermatogenesis (reproductive period) and in the post-reproductive period (data not shown). Figure 4 shows testis sections of a prereproductive lizard stained for PCNA together with the negative control for immunoreaction (Fig. 4A). Immunopositive material was found in the actively dividing germinal epithelium and was localized in the cytoplasm and nucleus of type I and II SPG of both control (Fig. 4B) and D-Asp-treated animals (Fig. 4C, D and E). Moreover, at time 0 the positivity was observed in SPG (Fig. 4b2) while SPDs remained negative (Fig. 4b1). At 3 (Fig. 4C) 

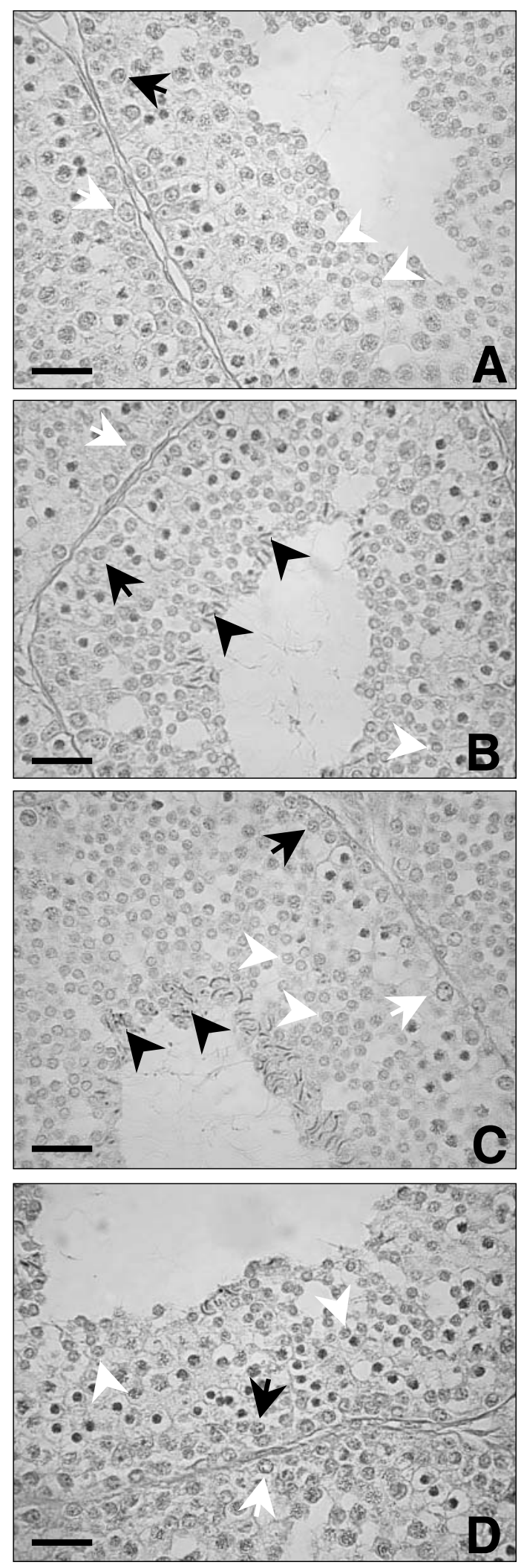

and $6 \mathrm{~h}$ (Fig. 4D) after D-Asp injection, immunopositive material was also localized in the nucleus of type I and II SPDs (Fig. 4c1 and $\mathrm{d} 1$ respectively). At $24 \mathrm{~h}$, the immunopositive elements for PCNA were comparable with the controls (Fig. 4e1 and e2).

The immunohistochemical results were assessed by morphometric analyses revealing an increase of immunopositive elements in the testis treated with D-Asp. At time 0 the number of immunopositive elements was $606 \pm 62$ cells $/ \mathrm{mm}^{2}$. At 3 and $6 \mathrm{~h}$ after D-injection this value was significantly increased $(710 \pm 37$ and $916 \pm 55$ cells $/ \mathrm{mm}^{2}$ respectively) to be $1 \cdot 2 \quad(P<0 \cdot 05)$ and $1.5(P<0 \cdot 01)$ times greater than time 0 . Within 15 and $24 \mathrm{~h}$ the number of immunopositive cells gradually decreased to the baseline levels $(674 \pm 48$ and $622 \pm 52$ cells $/ \mathrm{mm}^{2}$ respectively).

\section{Discussion}

We provide physiological evidence of naturally occurring free D-Asp in the testis of the lizard Podarcis s. sicula. Gonadal levels of this amino acid undergo fluctuations throughout the sexual cycle: the highest concentration of D-Asp is present in the testis of lizards during the reproductive period. The testis shows a very high and relatively rapid ability to take up and accumulate exogenously administered D-Asp, particularly in the pre- and post-reproductive phases rather than in the reproductive phase, probably because of the highest endogenous D-Asp present in the gonad during the latter period. D-Asp administered intraperitoneally (D'Aniello et al. 1996) or intravenously (Imai et al. 1997) is incorporated by the pineal gland, pituitary, testis and adrenal gland of the rat. Cultured rat pinealocytes can take up exogenous D-Asp intensively (Takigawa et al. 1998). The L-Glu transporter, which has been identified in the rat pineal gland (Yamada et al. 1997) may be responsible for this uptake since this transporter has affinity for D-Asp in addition to L-Glu and L-Asp (Kanai \& Hediger 1992, Pines et al. 1992). The capacity of the testis to concentrate D-Asp suggests the presence of L-Glu receptors, whose expression could vary in correlation with gonadal activity. In our report, we also investigated the effects of other D-/L-amino acids (D-Ala, D-Glu, L-Asp): these are present in low amounts in the testicular tissue and are not significantly taken up by the

Figure 3 Histology (A-D) of the testis of Podarcis s. sicula, during the pre-reproductive period and following short-term treatment with D-Asp (0, 3, 6 and 15-24 h). The sections were stained with hematoxylin and eosin. At $3 \mathrm{~h}$ (B) and $6 \mathrm{~h}$ (C) after D-Asp injection, elongated spermatids appeared at the lumen proximity (black arrowheads). I SPG, white arrows; II SPG black arrows; SPDs, white arrowheads; elongated SPDs, black arrowheads. Magnification, $\times 500$. 

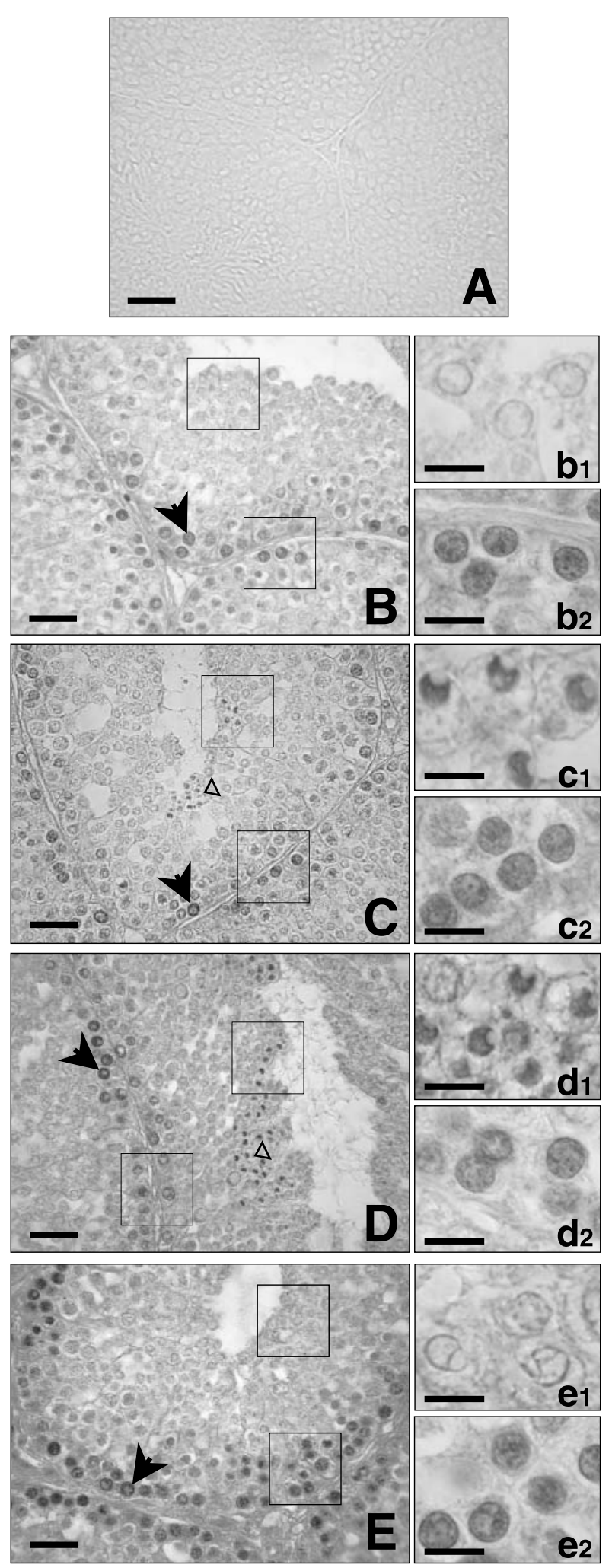

gonad. This indicates that D-Asp is the only amino acid that is actively taken up by the testis.

Comparison of the testicular D-Asp content with sex hormone levels, in both gonadal and plasma concentrations, indicates a direct correlation between D-Asp and testosterone titres and a reverse correlation between $\mathrm{D}$-Asp and $17 \beta$-estradiol levels during the cycle. The highest concentration of D-Asp in the testis coincides with the highest levels of testosterone; conversely, the lowest D-Asp concentration occurs in the testis when the $17 \beta$-estradiol level is at its highest point. The D-Asp profile in the testicular tissue and its correlation with testosterone titer led us to propose that D-Asp could be endowed with the control of the synthesis and release of steroid hormones by the gonad. In vivo experimental results support this hypothesis. The exogenous D-Asp and its parallel uptake in the gonad induce a significant increase in both plasma and testicular testosterone concentration. This effect is observed in all phases of the sexual cycle although it is particularly evident in the pre- and post-reproductive periods. This hormonal trend is summarized in Fig. $5: 3 \mathrm{~h}$ after D-Asp injection in the testis, testosterone levels are the highest and these events are paralleled with a significant decrease of $17 \beta$-estradiol levels. A similar trend in sex hormone levels is observed in the blood although the peak is shifted by $3 \mathrm{~h}$, i.e. $6 \mathrm{~h}$ after D-Asp injection. Sex hormones were restored to basal levels within 15-24 h. These effects are supposedly due to a local action of D-Asp on sex hormone synthesis, since, according to studies carried out on the rat, this amino acid is usually present in rat endocrine compartments of the testis, such as Leydig and Sertoli cells (D'Aniello et al. 1996, 1998b, Nagata et al. 1999a). No endocrine effects were observed following the administration of other amino acids (D-Ala, or D-Glu or L-Asp) (data not shown). These relationships between D-Asp and sex hormones, therefore, suggest that, as already shown in several mammalian species (D'Aniello et al. 2000a,b, Nagata et al. 1999a) and in the green frog (Raucci et al. 2004), there is also a putative positive intervention of $\mathrm{D}$-Asp on testosterone production in male lizards. In addition, our findings suggest a novel function of the amino acid, i.e. a negative influence on $17 \beta$-estradiol synthesis.

To date, other studies have reported the involvement of D-Asp in hormone synthesis and release. Takigawa et al.

Figure 4 Immunohistochemistry for PCNA (A-E) in the testis of Podarcis s. sicula, during the pre-reproductive period and following short-term treatment with D-Asp (0, 3, 6 and 15-24 h). (A) Negative control for PCNA. (B) Positive reaction in the cytoplasm and the nucleus of SPG (arrows) at time 0 . At $3 \mathrm{~h} \mathrm{(C)} \mathrm{and} 6 \mathrm{~h}$ (D) after D-Asp injection, the immunopositivity is also localized in the type I and II SPDs $(\triangle)$. At $15-24 \mathrm{~h}(\mathrm{E})$ the immunopositivity of the germinal epithelium of the testis is similar to the control $(\times 500)$. The adjacent sections (b1-e1) and (b2-e2) show higher magnification of represented cell types immunopositive to PCNA $(\times 1000)$. 


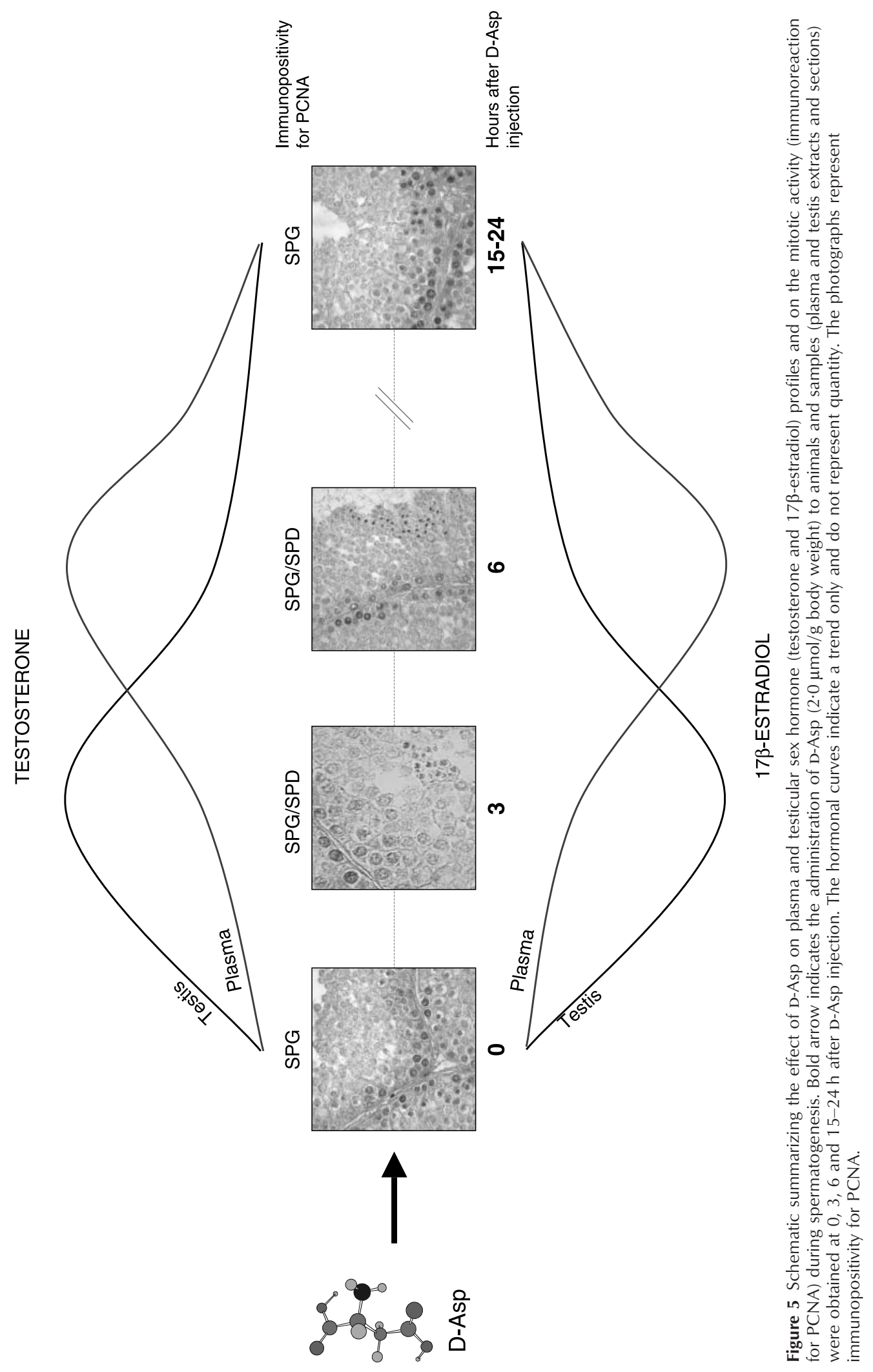


(1998) demonstrated that D-Asp affected melatonin synthesis in the pineal gland. Furthermore, exogenous D-Asp stimulates the release of luteinizing hormone (LH), growth hormone and prolactin in the anterior pituitary of rat (D'Aniello et al. 2000a,b). Unfortunately, in reptiles, LH measurements were not possible due to the lack of a suitable antibody which cross-reacts with reptilian LH. It has been shown that an appreciable amount of D-Asp is also present in the Leydig and Sertoli cells (D'Aniello et al. 1996, 1998b, Nagata et al. 1999a) and immunolocalized in the spermatids (Sakai et al. 1998b). Our data are consistent with the observation that in the rat, D-Asp levels show a strong correlation with testosterone during development when exogenous D-Asp stimulates the synthesis of testosterone without affecting progesterone synthesis (D'Aniello et al. 1996). Recently, Raucci et al. (2004) revealed that D-Asp-injected frogs have increased testosterone levels in both testis and plasma. Nevertheless, D-Asp has been reported to suppress testosterone production in isolated ovarian follicles (Di Fiore et al. 1998) and in vitro evidence demonstrated that the amino acid is involved in the modulation of aromatase activity, which converts testosterone to $17 \beta$-estradiol (Assisi et al. 2001). The physiological mechanism behind the involvement of D-Asp in the enhancement of aromatase activity has not been established. It is possible that a pool of inactive aromatase is present and is successively transformed into active forms by D-Asp. This hypothesis is consistent with findings that D-Asp enhances StAR through either gene expression or activation of the inactive form (Nagata et al. 1999b). Considering the data, we are inclined to argue that the different involvement of D-Asp in the hormone synthesis could be sex and/or species dependent. The high level of $\mathrm{D}$-Asp detected in the testis of the lizard during the sexual cycle implies the presence of an aspartate racemase activity, which requires conversion of L-Asp to D-Asp (Wolosker et al. 2000). On the other hand, in the cerebrospinal ganglion of the protocordate Ciona intestinalis, D-Asp has been synthesized from L-Asp by an aspartate racemase (D'Aniello et al. 2003). However, indirect evidence of D-Asp biosynthesis in mammalian cells was first demonstrated by Long and co-workers (1998). Although an extragonadal source of endogenous D-Asp cannot be ruled out, our biochemical determination of racemase indicates that this enzyme activity can be demonstrated in testis samples and is higher during the reproductive phase when the endogenous D-Asp content in the testis is higher. In addition, we report that D-Asp synthesis occurs in both the liver and testis of the lizard Podarcis s, sicula. Unlike the liver, where D-Asp concentration remains unchanged, the testis shows a significant fluctuation of racemase activity throughout the reproductive cycle. D-Asp peaks when testosterone levels are at their highest and spermatogenesis is also active (reproductive period). Thus, we are inclined to argue that at least some of the D-Asp formed in the testis can contribute to the production of more testosterone.
Here we investigated the in vivo effects of D-Asp on the mitogen activity of the testis. Our study implies that D-Asp might participate in the spermatogenesis and suggests a putative biological role for this amino acid in germinal epithelium proliferation. PCNA was predominantly localized in the cytoplasm and nucleus of SPG. When D-Asp was administered intraperitoneally, SPG multiplication rapidly increased: at 3 and $6 \mathrm{~h}$ after D-Asp injection, the PCNA immunopositivity was also observed in the SPDs. This effect was reversible because at $24 \mathrm{hrs}$ the immunopositivity returned to control levels. It is known that the mitotic activity observed in testis fluctuates during the reproductive cycle. In fact, it is highest in the reproductive period when the testosterone levels reported in both testis and plasma are at maximum concentrations (Chieffi et al. 2001). In addition, no increases of PCNA expression in the testis following D-Ala, or D-Glu or L-Asp administration were observed (data not shown). Figure 5 shows a summarized scheme for both the endocrine and the spermatogenetic effects of D-Asp on the testis of Podarcis s. sicula.

The effect of D-Asp treatment on mitotic activity of the testis could be mediated by androgen hormones. In fact, the highest levels of circulating testosterone are beneficial for spermatogenesis, and development and maturation of typical androgen-dependent target organs (Delrio et al. 1980, Varriale \& Serino 1994, Di Fiore et al. 2002, Raucci et al. 2004). It has been shown that PCNA is expressed strongly in the testes of eels treated with 11 ketotestosterone (11-KT) (Miura et al. 2002). On the other hand, $11-\mathrm{KT}$ induces the activation of the kinase cascade through the extracellular signal-regulated kinases (ERKs) phosphorylation (Walker et al. 1998). ERKs activity is well documented in the testis of Rana esculenta and Podarcis s. sicula during the sexual cycle and its fluctuations are paralleled with spermatogonial multiplication (Chieffi et al. 2000, 2001). Further studies will be required for an understanding of the possible mechanism by which D-Asp induces the increase of PCNA in the testis of Podarcis s. sicula, favoring spermatogenesis.

Recently, Wang et al. (2002) demonstrated that naturally occurring free D-Asp is subcellularly localized to the heterochromatin in the nucleoli of magnocellular neurosecretory neurons in the rat hypothalamus and also in the pituitary; they hypothesized that D-Asp has a physiological role in the nuclear function of mammals. Rat testis revealed immunoreactivity in the cytoplasm of germ cells and interstitial cells, and in the nuclei of the spermatogonia (Sakai et al. 1998a). At least two broad mechanisms for the function of free D-Asp in the nucleus could be proposed: D-Asp could directly interact with DNA and/or D-Asp could act on nuclear proteins to maintain the structure and/or active/inactive state of genes in order to control the regulation of proliferation and differentiation. Further studies are necessary to clarify the mechanism of action of D-Asp in the mitogen activity of the testis. Since androgens 
affect proliferation activity of the testis, an indirect effect of D-Asp on spermatogenesis cannot be excluded.

While considerable work still remains, evidence reported in this paper and in previous work to date, suggest that D-Asp is a critical regulatory molecule of the testis, and functions as a putative mediator in endocrine signaling and regulation.

\section{Funding}

This work was supported by an MIUR grant (cofin PRIN 2004, prot. 2004051955). The authors declare that there is no conflict of interest that would prejudice the impartiality of this scientific work.

\section{References}

Andò S, Panno ML, Ciarcia G, Imbrogno E, Buffone M, Beraldi E, Sisci D, Angelini F \& Botte V 1990 Plasma sex hormone concentrations during the reproductive cycle in the male lizard, Podarcis s. sicula. Journal of Reproduction and Fertility 90 353-360.

Andò S, Ciarcia G, Panno ML, Imbrogno E, Tarantino G, Buffone M, Beraldi E, Angelini F \& Botte V 1992 Sex steroids levels in the plasma and testis during the reproductive cycle of lizard Podarcis s. sicula Raf. General and Comparative Endocrinology 85 1-7.

Angelini F \& Botte V 1992 Spermatogenesis in reptiles: dynamic and regulatory aspects. In Sex Origin and Evolution, pp 211-230. Ed R Dallai. Modena, Italy: Mucchi.

Assisi L, Botte V, D'Aniello A \& Di Fiore MM 2001 Enhancement of aromatase activity by $\mathrm{D}$-aspartic acid in the ovary of the lizard Podarcis s. sicula. Reproduction 121 803-808.

Botte V \& Angelini F 1980 Endocrine control of reproduction in reptiles: the refractory period. In Steroids and their Mechanisms of Action in Nonmammalian Vertebrates, pp 201-212. Eds G Delrio \& J Brachet. New York: Raven Press.

Chieffi P, Franco R, Fulgione D \& Staibano S 2000 PCNA in the testis of the frog, Rana esculenta: a molecular marker of the mitotic testicular epithelium proliferation. General and Comparative Endocrinology 119 11-16.

Chieffi P, Nasti M, Fulgione D, Franco R 2001 Expression of PCNA in the testis of the lizard, Podarcis s. sicula: an endogenous molecular marker of mitotic germinal epithelium proliferation. Zygote 9 $317-322$.

D’Aniello A, Vetere A \& Petrucelli L 1993 Further study on the specificity of D-amino acid oxidase and of D-aspartate oxidase and time course for complete oxidation of D-amino acids. Comparative Biochemistry and Physiology B 105 731-734.

D'Aniello A, Di Cosmo A, Di Cristo C, Annunziato L, Petrucelli L \& Fisher G 1996 Involvement of D-aspartic acid in the synthesis of testosterone in rat testes. Life Sciences 59 97-104.

D'Aniello A, Di Fiore MM \& Fisher G 1998a Occurrence of $\mathrm{D}$-aspartic acid in animal tissues and its role in the nervous and endocrine systems. Trends in Comparative Biochemistry and Physiology 4 1-21.

D'Aniello A, Di Fiore MM, D'Aniello G, Colin FE, Lewis G \& Setchell BP 19986 Secretion of D-aspartic acid by the rat testis and its role in endocrinology of the testis and spermatogenesis. FEBS Letters 436 23-27.

D'Aniello A, Di Fiore MM, Fisher GH, Milone A, Seleni A, D'Aniello S, Perna AF \& Ingrosso D $2000 a$ Occurrence of D-aspartic acid and N-methyl-D-aspartic acid in rat neuroendocrine tissues and their role in the modulation of luteinizing hormone and growth hormone release. FASEB Journal 14 699-714.
D’Aniello G, Tolino A, D'Aniello A, Errico F, Fisher GH \& Di Fiore MM $2000 b$ The role of D-aspartic acid and N-methyl-D-aspartic acid in the regulation of prolactin release. Endocrinology 141 3862-3870.

D’Aniello A, Spinelli P, De Simone A, D'Aniello S, Branno M, Aniello F, Fisher GH, Di Fiore MM \& Rastogi RK 2003 Occurrence and neuroendocrine role of D-aspartic acid and $\mathrm{N}$-methyl-D-aspartic acid in Ciona intestinalis. FEBS Letters $\mathbf{5 5 2}$ 193-198.

Delrio G, Citarella F \& d'Istria M 1980 Androgen receptor in the thumb pad of Rana esculenta: dynamic aspects. Journal of Endocrinology 85 279-282.

Di Fiore MM, Assisi L, Botte V \& D'Aniello A 1998 D-Aspartic acid is implicated in the control of testosterone production by the vertebrate gonad. Studies on the female green frog Rana esculenta. Journal of Endocrinology 157 199-207.

Di Fiore MM, Chieffi Baccari G, Rastogi RK, di Meglio M, Pinelli C \& Iela L 2002 Hormonal regulation of secondary sexual characters. In Biology of Amphibia, vol VI, Endocrinology. Ed. W Heatwole. Sydney, Australia: Surrey Beatty \& Co.

Dunlop DS, Neidle A, McHale D, Dunlop DM \& Lajtha A 1986 The presence of free D-aspartic acid in rodents and man. Biochemical and Biophysical Research Communications 141 27-32.

Fisher GH, D’Aniello A, Vetere A, Padula L, Cusano GP \& Man EH 1991 Free D-aspartate and D-alanine in normal and Alzheimer brain. Brain Research Bulletin 26 983-985.

Fisher GH, Petrucelli L, Gardner C, Emory C, Frey WH 2nd, Amaducci L, Sorbi S, Sorrentino G, Borghi M \& D'Aniello A 1994 Free D-amino acids in human cerebrospinal fluid of Alzheimer disease, multiple sclerosis, and healthy control subjects. Molecular and Chemical Neuropathology 23 115-124.

Hamase K, Homma H, Takigawa Y, Fukushima T, Santa T \& Imai K 1997 Regional distribution and postnatal changes of D-amino acids in rat brain. Biochimica et Biophysica Acta 1334 214-222.

Hashimoto A \& Oka T 1997 Free D-aspartate and D-serine in the mammalian brain and periphery. Progress in Neurobiology $\mathbf{5 2}$ 325-353.

Hashimoto A, Nishikawa T, Oka T, Hayashi T \& Takahashi K 1993 Widespread distribution of free D-aspartate in rat periphery. FEBS Letters 331 4-8.

Hsu SM, Raine L \& Fanger H 1981 Use of avidin-biotin peroxidase complex $(\mathrm{ABC})$ in immunoperoxidase techniques: a comparison between $\mathrm{ABC}$ and unlabeled antibody (PAP) procedures. Journal of Histochemistry and Cytochemistry 29 577-580.

Imai K, Fukushima T, Hagiwara K \& Santa T 1995 Occurrence of $\mathrm{D}$-aspartic acid in rat brain pineal gland. Biomedical Chromatography 9 106-109.

Imai K, Fukushima T, Santa T Homma H, Sugihara J, Kodama H \& Yoshikawa M 1997 Accumulation of radioactivity in the brain and peripheral tissues including salivary gland after intravenous administration of C-14-aspartic acid. Proceedings of the Japan Academy 73 48-52.

Ishio S, Yamada H, Hayashi M, Yatsushiro S, Noumi T, Yamaguchi A \& Moriyama Y 1998 D-aspartate modulates melatonin synthesis in rat pinealocytes. Neuroscience Letters 249 143-146.

Kanai Y \& Hediger MA 1992 Primary structure and functional characterization of a high-affinity glutamate transporter. Nature $\mathbf{3 6 0}$ 467-471.

Lee JA, Homma H, Sakai K, Fukushima T, Santa T, Tashiro K, Iwatsubo T, Yoshikawa M \& Imai K 1997 Immunohistochemical localization of D-aspartate in rat pineal gland. Biochemical and Biophysical Research Communications 231 505-508.

Lee JA, Long Z, Nimura N, Iwatsubo T, Imai K \& Homma H 2001 Localization, transport, and uptake of D-aspartate in the rat adrenal and pituitary glands. Archives of Biochemistry and Biophysics 385 242-249. 
Long Z, Homma H, Lee JA, Fukushima T, Santa T, Iwatsubo T, Yamada R \& Imai K 1998 Biosynthesis of D-aspartate in mammalian cells. FEBS Letters 434 231-235.

Mazzi V 1977 Manuale di tecniche istologiche e istochimiche. Padova, Italy: Piccin Editore.

Miura C, Miura T \& Yamashita M 2002 PCNA protein expression during spermatogenesis of the Japanese eel (Anguilla japonica). Zoological Science 19 87-91.

Nagata Y, Homma H, Lee JA \& Imai K 1999a D-Aspartate stimulation of testosterone synthesis in rat Leydig cells. FEBS Letters 444 160-164.

Nagata Y, Homma H, Matsumoto M \& Imai K 1999 b Stimulation of steroidogenic acute regulatory protein (StAR) gene expression by D-aspartate in rat Leydig cells. FEBS Letters 454 317-320.

Negri A, Tedeschi G, Ceciliani F \& Ronchi S 1999 Purification of beef kidney D-aspartate oxidase overexpressed in Escherichia coli and characterization of its redox potentials and oxidative activity towards agonists and antagonists of excitatory amino acid receptors. Biochimica et Biophysica Acta 1431 212-222.

Neidle A \& Dunlop DS 1990 Developmental changes in free D-aspartic acid in the chicken embryo and in the neonatal rat. Life Sciences 46 1517-1522.

Paolucci M, Di Fiore MM, Ciarcia G \& Botte V 1992 Plasma sex steroid binding proteins (SSBP) in the male lizard, Podarcis s. sicula, during the reproductive cycle. General and Comparative Endocrinology 87 232-239.

Pines G, Danbolt NC, Bjoras M, Zhang Y, Bendahan A, Eide L, Koepsell H, Storm-Mathisen J, Seeberg E \& Kanner BI 1992 Cloning and expression of a rat brain L-glutamate transporter. Nature 360 464-467.

Raucci F, Assisi L, D’Aniello S, Spinelli P, Botte V \& Di Fiore MM 2004 Testicular endocrine activity is upregulated by D-aspartic acid in the green frog, Rana esculenta. Journal of Endocrinology 182 365-376.

Roelants H, Schneider F, Goritz F, Streich J \& Blottner S 2002 Seasonal changes of spermatogonial proliferation in roe deer, demonstrated by flow cytometric analysis of c-kit receptor, in relation to follicle-stimulating hormone, luteinizing hormone, and testosterone. Biology of Reproduction 66 305-312.

Sakai K, Homma H, Lee JA, Fukushima T, Santa T, Tashiro K, Iwatsubo T \& Imai K 1998 a Emergence of D-aspartic acid in the differentiating neurons of the rat central nervous system. Brain Research 808 65-71.

Sakai K, Homma H, Lee JA, Fukushima T, Santa T, Tashiro K, Iwatsubo T \& Imai K 1998 bocalization of D-aspartic acid in elongate spermatids in rat testis. Archives of Biochemistry and Biophysics 351 96-105.
Schell MJ, Cooper OB \& Snyder SH 1997 D-Aspartate localizations imply neuronal and neuroendocrine roles. PNAS 94 2013-2018.

Sharpe RM 1994 Regulation of spermatogenesis. In The Physiology of Reproduction, 2nd edn, vol 2, pp 1363-1434. Eds E Knobil \& JD Neill. New York: Raven Press.

Takigawa Y, Homma H, Lee JA, Fukushima T, Santa S, Iwatsubo T \& Imai K 1998 D-Aspartate uptake into cultured rat pinealocytes and the concomitant effect on L-aspartate levels and melatonin secretion. Biochemical and Biophysical Research Communications 248 641-647.

Varriale B \& Serino I 1994 The androgen receptor mRNA is up-regulated by testosterone in both the Harderian gland and thumb pad of the frog, Rana esculenta. Journal of Steroid Biochemistry and Molecular Biology 51 259-265.

Walker CW, Demian DJ, Kirby PJ, Blickarz CE \& Hallonquist H 1998 Interacting mitogenic pathways during spermatogonial G1/S phase traverse in the sea star Aesterias vulgaris. Annals of the New York Academy of Sciences 839 321-325.

Wang H, Wolosker H, Pevsner J, Snyder SH \& Selkoe DJ 2000 Regulation of rat magnocellular neurosecretory system by D-aspartate: evidence for biological role(s) of a naturally occurring free D-amino acid in mammals. Journal of Endocrinology 167 247-252.

Wang H, Wolosker H, Morris JF, Pevsner J, Snyder SH \& Selkoe DJ 2002 Naturally occurring free D-aspartate is a nuclear component of cells in the mammalian hypothalamo-neurohypophyseal system. Neuroscience 109 1-4.

Wolosker H, D’Aniello A \& Snyder SH 2000 D-aspartate disposition in neuronal and endocrine tissues: ontogeny, biosynthesis and release. Neuroscience 100 183-189.

Yamada H, Yatsushiro S, Yamamoto A, Hayashi M, Nishi T, Futai M, Yamagishi A \& Moriyama Y 1997 Functional expression of a GLT-1 type $\mathrm{NA}^{+}$-dependent glutamate transporter in rat pinealocytes. Journal of Neuroscience 69 1491-1498.

Zhang H, Xiong Y \& Beach D 1993 Proliferating cell nuclear antigen and p21 are components of multiple cell cycle kinase complexes. Molecular Biology of the Cell 4 897-906.

Zirkin BR 1993 Regulation of spermatogenesis in the adult mammal: gonadotropins and androgens. In Cell and Molecular Biology of the Testis, pp 166-188. Eds C Desjardins \& LL Ewing. New York: Oxford University Press.

Received in final form 2 September 2005

Accepted 13 September 2005

Made available online as an Accepted Preprint

30 September 2005 